\begin{tabular}{c} 
Volume and Issues Obtainable at Center for Sustainability Research and Consultancy \\
Journal of Business and Social Review in Emerging Economies \\
ISSN: 2519-089X (E): 2519-0326 \\
Volume 3: Issue 1 June 2017 \\
CSRᄃ \\
Journal homepage: www.publishing.globalcsrc.org/jbsee \\
\hline
\end{tabular}

\title{
Predictors of Employee Information Sharing Behavior using Social Media
}

\author{
${ }^{1}$ Tiny AzleenBintiYahaya, ${ }^{2}$ Khairuddin Bin Idris, ${ }^{3}$ Ismi Arif Ismail, ${ }^{4}$ Turiman Suandi \\ ${ }^{1}$ Department of Professional Development and Continuing Education, Universiti Putra Malaysia, 43400,Serdang, \\ Selangor Darul Ehsan, Malaysia. ciktiny@gmail.com \\ ${ }^{2}$ Department of Professional Development and Continuing Education, Universiti Putra Malaysia, 43400,Serdang, \\ Selangor Darul Ehsan, Malaysia. kidin@upm.edu.my \\ ${ }^{3}$ Department of Professional Development and Continuing Education, Universiti Putra Malaysia, 43400,Serdang, \\ Selangor Darul Ehsan, Malaysia. ismilina@gmail.com \\ ${ }^{4}$ Department of Professional Development and Continuing Education, Universiti Putra Malaysia, 43400,Serdang, \\ Selangor Darul Ehsan, Malaysia. tj@upm.edu.my
}

\begin{tabular}{l}
\hline ARTICLEDETAILS \\
\hline History \\
Revised format: May 2017 \\
AvailableOnline: June 2017 \\
\hline Keywords \\
Knowledge Sharing Behavior, \\
Social Media, \\
Attitude, \\
Mediator, \\
Readiness for Change
\end{tabular}

\section{JEL Classification:}

D80, L82

\begin{abstract}
Purpose:Social media application such as Blog, Wikipedia, Flickr, Facebook, Twitter, and Myspace, are currently become a useful medium of communication as well as sharing information especially in an organisation. This phenomenon effected not only individual all over the world but also employees in Malaysia organisations. Thus, this study is a work-in-progress that referring to a few theories and journals to identify employee's intrinsic attitude as a predictor that contribute to information sharing behavior using social media with the readiness for change as a mediator factor.

Design/Methodology/Approach: This study based on a review of several journal and theories related to individual behavior focusing on intrinsic attitude that has significantly contribute to employees' behavior to adapt with new technologies, which is in this study, social media.

Findings:The results shows that intention behavior, belief expectancy and attitude influence are the predictors for employees' intrinsic attitude and readiness for change comes as mediator factor that being predict to have a significant relationship with information sharing behavior using social media among the employee.

Implications/Originality/Value: The existence of readiness for change as mediator between employee's intrinsic attitude and information sharing behavior using social media among the employee of Government-Link Company can be taken into consideration for developing a new model of information sharing behavior using social media.
\end{abstract}

(C) 2017 The authors, under a Creative Commons AttributionNonCommercial 4.0

Corresponding author's email address: ciktiny@gmail.com

Recommended citation:Yahaya, T.A., Idris, K., Ismail,I.A. \&Suandi, T (2017).Predictors of Employee Information Sharing Behavior using Social Media.Journal of Business and Social Review in Emerging Economies, 3(1) 139-146.DOI:https://doi.org/10.26710/jbsee.v3i1.51

\section{Introduction}

In the world of information, communication and technology (ICT), online information sharing is very important to send and receive a latest news. According to the explanation by Davenport \& Prusak (1998), the word 'inform' has been interpreted as 'to give shape to' and 'information' is to give the receiver an 
insight about the look and the feel of the sent message. Therefore, the meaning of the message depends on of receiver interpretation, not of the sender. Before the existence of the internet world, sharing information was done in traditional ways such as face-to-face meetings, letters, telegrams, memos, circulars, or dissemination through notice boards. The information sent by the sender to the receiver can take hours or days or even for months to reach the receiver. However, with the advancement of ICT and the invention of the internet, information is more easily accessible, not only from the sender to one individual receiver but to a group of people simultaneously. Web 1.0 technologies such as email has facilitated the people doing businesses who wanted to share information in a quick period. However, the emergence of Web 2.0, namely social media application, made online information sharing become more attractive. Karakas (2012) explains in detail that the Web 2.0 or also called as "World 2.0" is known as an interactive and immersive digital ecosystem or mega-platform where the social media tools such as Wikipedia, Flickr, Blog, Facebook, Instagram, Twitter, Myspace, YouTube allow the employees to interact effectively. Social media Web 2.0 technology enables anyone to share information in a public forum on the Internet. According to Kane, et. al. (2010), social media Web 2.0 technology facilitates the information sharing throughout the whole world, without the boundaries of time and place. Information sharing can increase employee social capital by enhancing one's reputation among colleagues and the organization (Wasko \& Faraj, 2005).

According to Ardichvili, Page, \& Wentling (2003), they have found several motivational factors that contribute to employees' willingness to share their knowledge to virtual knowledge-sharing communities of practice. The basic concept in Unified Theory of Acceptance and Use of Technologies (UTAUT), by Venkatesh, Morris, Davis, \& Davis (2003) shows that for employees to actual use of information technologies, the individual reactions using information technologies is the main factor that contribute to the correlation between the individual intrinsic attitude factors and the actual behavior. This study will go further to discuss the predictor factors of intrinsic attitude that contribute to the information sharing behavior using social media.

Information sharing behavior has been studied in the management and business field with many respondents such as civil servant (Olatokun \& Nwafor, 2012), health-care professional (Hara \& Hew, 2007), academic community of practice (Nistor, et. al., 2012), teachers (Lin \& Chen, 2009), group of community (Park, et. al., 2014) and others. In this study, the researcher focused to information sharing behavior using social media as the dependent variable.

\section{Literature Review}

This study is based on a number of theories and models of previous studies. The main theory is prevailed from Individual Expectancy Motivation Theory by Vroom, 1964. Vroom's Expectations Motivation Theory states that a person will make a decision to do or not do a thing depending on the expectations of what can be gained from doing or not doing it (Geiger \& Cooper, 1996). According to Self Determination Theory (SDT) by Ryan \& Deci, (2000), an individual motivation factors are divided into two factors namely Intrinsic and extrinsic factors. Individual intrinsic attitude factors are related to internal need and derive from the expectation of the benefits that the individual can gain. While extrinsic factors are the external factors that, encourage and give influence to the individual to do, not to do something, or to make decision.

This study also refers to the Theory of Planned Behavior (TPB) by Ajzen (1991) which states that individual behavior is designed to take into account internal and external factors that led to the intentions and actions of individuals. TPB theory were also discussed by Bock \& Kim (2002) who explained the predictors of the individual's intrinsic attitude. Unified Theory of Acceptance and Use Technologies (UTAUT) by Venkatesh, et. al. (2003) is the main model and concepts used in this review. UTAUT explains the significance of technology adoption in an organization based on the construct of individual's attitude such as performance expectancy, effort expectancy, social influence and facilitating conditions and studied its significant relationship with moderator factors such as gender, age, experience, and 
willingness to use towards use behavior. This study also incorporated the Change Theory by Lewin, K (1946). This Change Theory states that in every input and output of any matter, there is an element of transformation in between. Further to this, mediating affect in this study is referring to the study that has been done by Holt, et. al, (2007) which states that the outcome of behavior change needs to have an element of readiness for change as mediator factor.

\section{Methodology}

\subsection{Theorizing Information Sharing}

Information sharing is a type of social interaction in the community (Bock \& Kim, 2002), in an organization Yusof, et. al. (2012), in a group of the community of practice (Ranjbar \& Maheswaran, 2014), and also in people with the same interest (Tseng \& Kuo, 2014). Information sharing occurs due to the behavior of individuals who are willing to share that information with others (Kuntz \& Gomes, 2012). The definition of information sharing behavior by Sharratt \& Usoro (2003) stated that information sharing is an example in response to the request from the conduct of members of one group or party to get help in order to understanding any members or other parties to contribute what they know. Studies by Tohidinia \& Mosakhani (2010) stated that employees feel that by virtue of information sharing, they will contribute to the achievement of the desired result. The finding of the research showed that the relationship of reciprocity is expected to have a positive effect on the attitude towards good information sharing. Others than that, Personality Theory, Self-Discrepancy Theory, Organizational Control Theory, Organizational Support Theory, Pro-Social Behavior, Hierarchy of Needs Theory, Behavior Economics Theory, Consumer Choice Behavior have taken into consideration to measure the information sharing relationship and it predictors to measure the individual information sharing behavior specifically.

\subsection{Information sharing using social media}

According to Lin \& Joe (2011), information sharing, just like knowledge sharing, with many studies carried upon on, to see the readiness of an individual to share or not to share the information. Referring to studies done by previous researcher who studied on knowledge sharing among employee (Agnihotri, et. al., 2012; Burgess, 2005; Tangaraja, et. al., 2015), none of the studies give an attention to the employee's information sharing behavior through social media using Web 2.0 application and also none of any study focused for the GLC employees. Malaysian government, through Malaysian Administrative Modernization and Management Planning Unit (MAMPU), one of the prominent government agencies in Malaysia that responsible for 'modernizing and reforming' the public sector activities in Malaysia has come out with circular to all government agencies, allows the usage of social media as a medium of sharing information to public. MAMPU also proposed to Malaysian government agencies unit to give a permission to an employee to use social media application as medium of information sharing that related to the organization.

\subsection{Information sharing in Government-Linked Company (GLC)}

Apart from public service organizations (government) and private organizations, in Malaysia, there is an organization called the Government- Linked Company (GLC). In 2004, the Putrajaya Committee on GLC High Performance or known by the acronym PCG was established under the monitoring of Khazanah Nasional Berhad for holding the GLC transformation program. The program aims to ensure higher improvement under selected GLIC's organizations to become a viable entity and high performance in term of capital gain. Emphasis on information sharing method using social media Web 2.0 technology is expected to facilitate the presentation and dissemination of information to a lot of parties, including the employees of the organization itself and also the people who related to the development of the GLC transformation program from within and outside the country.

\subsection{The importance of information sharing behavior in GLC}

The arrival of Web 2.0 applications introduces social media as medium of information sharing and practice in an organization (Paroutis \& Saleh, 2009). This application can interact effectively between 
individual and group of community of practice (Park et al., 2014) especially between organization and the client. Interactive way of communication gives many advantages to employees of the organization to deliver and receive information within a short period of time (Ardichvili et al., 2003). Most of the GLC through their website shows that they are using a few social media application as medium of sharing and update their activities, but some application is not fully utilize. Researcher found that there was a case that a GLC never update their social media application such as Facebook. They did not reply to the user's question. This raises the user's dissatisfaction and they leave a bad comment to the company. By having this kind of problem, there is a need to human resource management (HRM) to look into this issue and find the solution to recover this matter. One of the solution is to allow the employee to use social media application within the company and give the responsibility to the employee to interact with the client and public. To do this, HRM also must take into consideration the behavior of the employee towards information sharing using social media. HRM also needs to identify the predictors' factor that related to the behavior; therefore, the implementation can be done accordingly.

\section{Discussion and Findings}

\subsection{Predictors of information sharing behavior}

This study is focusing on the predictors' of information sharing behavior using social media. Individual intrinsic attitude with the readiness for change as mediator have been identified to have relationship towards information sharing behavior using social media among GLC's employees.

\subsubsection{Individual's Intrinsic Attitude}

Venkatesh et al. (2003) in UTAUT identifies three direct determinants of behavioral intention to use a technology. These three determinants namely performance expectancy, effort expectancy and social influencebecome a reference to this study. Taking into account the Expectancy Theory(Vroom, 1964), Change Theory by Lewin (1946) and TPB by Ajzen (1991), the independent variable in this study will focus on intrinsic attitude of the employees. TPB highlighted intention as an element that will determine the change of employee's behavior. Demographic factors will not be discussed in depth in the context of this study because the focus of this study is to estimate the intrinsic attitude of employees to share information using social media in organizations. Therefore, under the factor of individual's intrinsic attitude, this study focus on three constructs as predictors for this study namely: (1) intention of behavior, (2) belief expectancy and (3) attitude influence.

Theory of Reasoned Action (TRA) by Fishbein \& Ajzen (1975)assumes that human beings are usually quite rational and make systematic use of information available to them. This theory mentioned that the attitude of an individual derives from psychological behavioral. This is the degree of positive feelings of an employee about sharing the information through social media. Research by Bock \& Kim (2002) explained that the employee's expected values have significant direct relationship towards information sharing behavior. When employees know that he will benefit when engaging in the act of sharing information through social media, the expected rewards will be high and positive. Three component has been discussed under the individual's intrinsic attitude construct. The component consists of intention of behavior, belief expectancy and attitude influence. Hence, this study is to confirm this relationship.

\subsubsection{Readiness for Change as mediator}

According to Kurt Lewin's Theory of Change, one must do a transformation to ensure the input become a result. This theory expresses the importance of transformation and one is ready to accept change (Schein, 1999). This study is to identify the degree of willingness of employee in his readiness for change to use social media as a medium for sharing information. This study proposed the readiness for change as mediator between the predictors and information sharing behavior using social media. By referring to Holt et. al (2007), the elements of readiness for change become a mediating affect to an outcome of behavior in organization. Readiness for change influences from several perspectives such as content, process, context, as well as the individuals involved, and collectively reflect the extent to which individuals or groups of individuals tend to accept the change. 


\subsubsection{Proposed an integrated model of information sharing behavior using social media}

After taking into consideration of the independent variables from past literature, lead journal, as well as main model and theories, this study chooses three construct namely intention behavior, belief expectancy and attitude influence as the predictors for employees' intrinsic attitude that being predict to have a significant relationship with information sharing behavior using social media among the GLC employees. This study expanding the previous model of research of information sharing behavior (Wu, 2012) by adding a mediator to see whether or not it is significant in the relationship between both variables. Since there are expectations of what can be gained, then, in the theory of planned behavior, employees are expected to assess the impact and importance of the change either accept or reject the information sharing using social media (Jalilvand \& Samiei, 2012). The mediator factor for this study is readiness for change. Future research is to identify the significantly effect of this factor mediating the independent variables and dependent variable. Summarizing from previous research, this study predicts that individual's intrinsic attitude would influence the sharing information behavior. Taking into consideration Kurt Lewin's theory, to put readiness for change as a mediating variable.

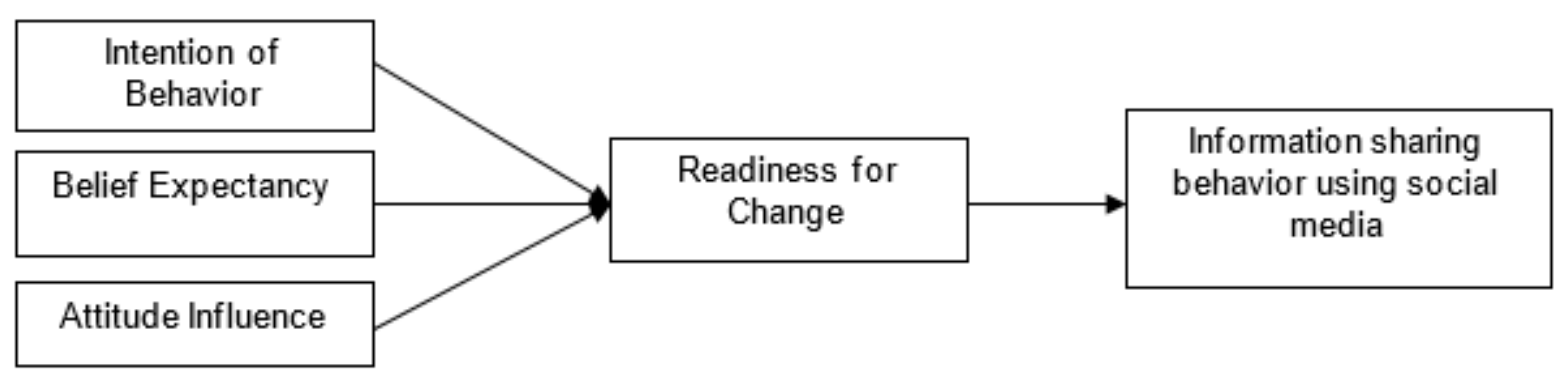

Figure 1: Basic concept underlying for this research key area

\section{Conclusion and recommendation}

The aim of this study is to identify the predictors of intrinsic towards employee's behavior of sharing information through social media. Throughout the theories and models of earlier studies, three constructs were identified as predictors for this study namely: (1) intention of behavior, (2) belief expectancy and (3) attitude influence. In particular, this study hypothesized each predictor towards employee's behavior of sharing information through social media. This study also predicted that readiness for change significant as a mediator who mediates the relationship between the individual intrinsic attitude predictors and employee's information sharing behavior using social media. The hypotheses should be made to see the mediating effect of readiness for change. This study is proposing the future researcher to specifically select an employee of Government-Linked Companies (GLC) in Malaysia as the respondents. While the study was about the organization, most of the studies in Malaysia focused on the government agencies, universities, banking industries, schools, private colleges or private companies but none of the studieswere focused on Government-Linked Company (GLC) especially on the behavior of the employees. GLC, in fact, plays a significant role in providing profit and generating income for the country. This study is expected to have a long-term implication for the management of human resources. These findings also gave a suggestion to the decision makers to make some improvements in human resource management policies and the staff handbook. This study is expected to create awareness among policy makers and top management of companies to realize, that in order to compete and to be at the same level as developed countries, the digital technology should be taken into account. The use of ICT should be extended without any restrictions but with an element of awareness. Not only that, this research proposal is expected to give more space to other studies to fill the gaps and to contribute to the study findings in the world of high-impact research. By implementing ICT-based initiatives, it will increase the ICT literacy among the employees and would bring higher success to the company globally. 
In future, this paper proposed to other researcher to deeply focus to the predictor's determinant and to further research by using quantitative method. Researcher recommends to other researcher to gather the questionnaire item based on the predictor's determinant. The set of questionnaire shall be distributed among the selected employees in Malaysian Government-Linked Company (GLC) to identify its significant and the relationship between the variables. The data shall be analyzed using Structural Equation Model (SEM) because it could entertain latent constructs with multiple indicators as well as the usual observed variables into the model concurrently (Zainudin, 2015).

\section{References}

Agnihotri, R., Kothandaraman, P., Kashyap, R., \& Singh, R. (2012). Bringing "Social" into Sales: The Impact of Salespeople's Social Media Use on Service Behaviors and Value Creation. Journal of Personal Selling and Sales Management, 32(3), 333-348. http://doi.org/10.2753/PSS08853134320304

Ajzen, I. (1991). The theory of planned behavior. Organizational Behavior and Human Decision Processes, 50(2), 179-211. http://doi.org/10.1016/0749-5978(91)90020-T

Ardichvili, A., Page, V., \& Wentling, T. (2003). Motivation and barriers to participation in virtual knowledge-sharing communities of practice. Journal of Knowledge Management, 7(1), 64-77. http://doi.org/10.1108/13673270310463626

Bock, G.-W., \& Kim, Y.-G. (2002). Breaking the Myths of Rewards: An Exploratory Study of Attitudes about Knowledge Sharing. Information Resources Management Journal, 15(2), 14-21. http://doi.org/10.4018/irmj.2002040102

Burgess, D. (2005). What Motivates Employees to Transfer Knowledge Outside Their Work Unit? Journal of Business Communication, 42(4), 324-348. http://doi.org/10.1177/0021943605279485

Davenport, T. H., \& Prusak, L. (1998). Working Knowledge: How Organizations Manage What They Know. Boston: Harvard Business School Press.

Fishbein, M., \& Ajzen, I. (1975). Belief Attitude, Intention and Behavior. An Introduction to Theory and Research. Philosophy \& Rhetoric, 10(2), 130-132.

Geiger, M. A., \& Cooper, E. A. (1996). Using Expectancy Theory to Assess Student Motivation. Issues in Accounting Education, 11(1), 113-129. Retrieved from http://p2047ezproxy.msu.edu.proxy1.cl.msu.edu/login?url=http://search.ebscohost.com.proxy1.cl.msu.edu/login. aspx ?direct $=$ true $\& d b=b$ th $\& A N=9605080856 \&$ site $=$ ehost-live $\&$ scope $=$ site

Hara, N., \& Hew, K. F. (2007). Knowledge-sharing in an online community of health-care professionals. Information Technology \& People, 20(3), 235-261. http://doi.org/10.1108/09593840710822859

Holt, D. T., Armenakis, a. a., Feild, H. S., \& Harris, S. G. (2007). Readiness for Organizational Change: The Systematic Development of a Scale. The Journal of Applied Behavioral Science, 43(2), 232255. http://doi.org/10.1177/0021886306295295

Jalilvand, M. R., \& Samiei, N. (2012). destination choice : Testing the theory of planned behavior (TPB) The impact of electronic word of mouth on a tourism destination choice Testing the theory of planned behavior ( TPB ). http://doi.org/10.1108/10662241211271563

Kane, K., Robinson-Combre, J., \& Berge, Z. L. (2010). Tapping into social networking:: Collaborating enhances both knowledge management and e-learning. Vine, 40(1), 62-70. http://doi.org/10.1108/03055721011024928

Karakas, F. (2012). Reorienting self-directed learning for the creative digital era, 0 . http://doi.org/10.1108/03090591211255557

Kuntz, J. R. C., \& Gomes, J. F. S. (2012). Transformational change in organisations: a self-regulation approach. Journal of Organizational Change Management, 25(1), 143-162. http://doi.org/10.1108/09534811211199637

Lewin, K. (1946). Action Research and Minority Problems. Journal of Social Issues, 2, 34-46. http://doi.org/10.1111/j.1540-4560.1946.tb02295.x

Lin, C.-P., \& Joe, S.-W. (2011). To Share or Not to Share: Assessing Knowledge Sharing, Interemployee Helping, and Their Antecedents Among Online Knowledge Workers. Journal of Business Ethics, 
108(4), 439-449. http://doi.org/10.1007/s10551-011-1100-x

Lin, C., \& Chen, M. (2009). Factors Affecting Teachers â€ ${ }^{\mathrm{TM}}$ Knowledge Sharing Behaviors and Motivation : System Functions that Work. Information Research, 1-8.

Nistor, N., Baltes, B., \& Schustek, M. (2012). Knowledge sharing and educational technology acceptance in online academic communities of practice. Campus-Wide Information Systems, 29(2), 108-116. http://doi.org/10.1108/10650741211212377

Olatokun, W., \& Nwafor, C. I. (2012). The effect of extrinsic and intrinsic motivation on knowledge sharing intentions of civil servants in Ebonyi State, Nigeria. Information Development, 28(3), 216 234. http://doi.org/10.1177/0266666912438567

Park, J. H., Gu, B., Leung, A. C. M., \& Konana, P. (2014). An investigation of information sharing and seeking behaviors in online investment communities. Computers in Human Behavior, 31, 1-12. http://doi.org/10.1016/j.chb.2013.10.002

Paroutis, S., \& Saleh, A. Al. (2009). Determinants of knowledge sharing using Web 2.0 technologies. Journal of Knowledge Management, 13(4), 52-63. http://doi.org/10.1108/13673270910971824

Ranjbar, A., \& Maheswaran, M. (2014). Using community structure to control information sharing in online social networks. Computer Communications, 41, 11-21. http://doi.org/10.1016/j.comcom.2014.01.002

Ryan, R. M., \& Deci, E. L. (2000). Intrinsic and Extrinsic Motivations: Classic Definitions and New Directions. Contemporary Educational Psychology, 25(1), 54-67. http://doi.org/10.1006/ceps.1999.1020

Schein, E. H. (1999). Kurt Lewin's Change Theory in the Field and in the Classroom: Notes Toward a Model of Managed Learning. Reflections: The SoL Journal. http://doi.org/10.1162/152417399570287

Sharratt, M., \& Usoro, A. (2003). Understanding Knowledge-Sharing in Online Communities of Practice. Electronic Journal on Knowledge Management, 1(2), 187-196.

Tangaraja, G., Rasdi, R. M., Ismail, M., \& Samah, B. A. (2015). Fostering knowledge sharing behaviour among public sector managers: a proposed model for the Malaysian public service. Journal of Knowledge Management, 19(1), 121-140. http://doi.org/doi:10.1108/JKM-11-2014-0449

Tohidinia, Z., \& Mosakhani, M. (2010). Knowledge sharing behaviour and its predictors. Industrial Management \& Data Systems, 110(4), 611-631. http://doi.org/10.1108/02635571011039052

Tseng, F.-C., \& Kuo, F.-Y. (2014). A study of social participation and knowledge sharing in the teachers' online professional community of practice. Computers \& Education, 72, 37-47. http://doi.org/10.1016/j.compedu.2013.10.005

Venkatesh, V., Morris, M. G., Davis, G. B., \& Davis, F. D. (2003). User Acceptance of Information Technology: Toward a Unified View. MIS Quarterly, 27(3), 425-478.

Vroom, V. H. (1964). Work and Motivation. New York: Wiley.

Wasko, M. M., \& Faraj, S. (2005). Why should I share? Examining social capital and knowledge contribution in electronic networks of practice. MIS Quarterly, 29(1), 35-57. Retrieved from http://www.jstor.org/stable/25148667

$\mathrm{Wu}, \mathrm{Y}$. (2012). An integrated theoretical model for determinants of knowledge sharing behaviours. Kybernetes, 41(10), 1462-1482. http://doi.org/10.1108/03684921211276675

Yusof, Z. M., Ismail, M. B., Ahmad, K., \& Yusof, M. M. (2012). Knowledge sharing in the public sector in Malaysia: a proposed holistic model. Information Development, 28(1), $43-54$. http://doi.org/10.1177/0266666911431475

Zainudin Awang. (2015). SEM made simple: A gentle approach to learning Structural Equation Modeling. Bangi: MPWS Publication Sdn Bhd. 
